other causes, adjusted for competing causes, $\left(\mathrm{q}_{\mathrm{x},-\alpha}\right)$ is therefore

$$
q_{x,-a}=\frac{d_{x,-a}}{l_{x}-\frac{1}{2} d_{x, a}}
$$

where $d_{x}$ is the number of deaths in age interval ( $x$, $\mathrm{x}+1$ ) due to the cause $\alpha, d_{x,-\alpha}$ is the number of deaths in age interval $(\mathrm{x}, \mathrm{x}+1)$ due to all other causes than $\alpha$, and $l_{x}$ is the number of survivors to age $\mathrm{x}$ (of the all causes life table cohort). The life table cohort is at risk for this adjusted force of mortality from other causes until extinction. ${ }^{2}$

The expected life time costs at birth after elimination of cause $\alpha\left(\mathrm{LEC}_{-\alpha}\right)$ are given by

$$
L E C_{-a}=\sum_{x}\left(\frac{C_{x,-a}}{N_{x}} * L_{x,-a}\right)
$$

where $\mathrm{C}_{\mathrm{x},-\alpha}$ represents the costs in the age interval $(\mathrm{x}, \mathrm{x}+1)$ made for all diseases other than $\alpha$ and $\mathrm{L}_{\mathrm{x},-\alpha}$ gives the life years lived in the age interval $(x, x+1)$ after elimination of cause $\alpha$.

1 Fries JF, Koop CE, Beadle CE, Cooper PP, England MJ, Greaves RJ, et al. Reducing health care costs by reducing the need and demand for medical services. N Engl J Med 1993;329:321-5.
2 Namboodiri K, Suchindran CM. Life table techniques and their application. Orlando: Academic Press, 1987:92-109.

3 Koopmanschap MA, van Roijen L, Bonneux L. Cost of illness in the Netherlands. Rotterdam: Department of Public Health: Erasmus University, 1991.(In Dutch.)

4 van Roijen L, Koopmanschap MA, Bonneux L. The cost of illness. Ned Tijdschr Geneeskd 1992;136:74-80.(In Dutch.)

5 Koopmanschap MA, van Roijen L, Bonneux L, Bonsel GJ, Rutten FFH, van der Maas PJ. Costs of diseases in an international perspective. Eur J Public Health 1994;4:258-64.

6 Statistics Netherlands. Deaths by causes of deaths, age and gender. Voorburg: Central Bureau of Statistics, published annually.

7 Shryock HS, Siegel JS. The life table. The methods and materials of demography. San Diego/New York: Academic Press, 1976:249-71.

8 Doll R, Peto R. Sources of bias in estimating trends in cancer mortality, incidence and curability. J Natl Cancer Inst 1981;66:1270-81.

9 Nusselder WJ, Van der Velden K, Van Sonsbeek JLA, Lenior ME, Van den Bos GAM. The elimination of selected chronic diseases in a population: the compression and expansion of morbidity. Am J Public Health 1996;86:187-94.

10 Russell L. Is prevention better than cure? Washington DC: Brookings Institute, 1986:116.

11 Lubitz J, Beebe J, Baker C. Longevity and Medicare expenditures. N Engl J Med 1995;332:999-1003.

12 Fries JF. Aging, natural death, and the compression of morbidity. N EnglJ Med 1980;303:130-5.

13 Rose G. The strategy of preventive medicine. Oxford: Oxford University Press, 1992:4.

14 World Health Organisation. International statistical classification of disease, injuries and causes of death. 9th revision. Geneva: World Health Organisation, 1977.

(Accepted 26 August 1997)

\title{
First sexual intercourse: age, coercion, and later regrets reported by a birth cohort
}

\author{
Nigel Dickson, Charlotte Paul, Peter Herbison, Phil Silva
}

\begin{abstract}
Objectives: To investigate how age at first sexual intercourse is related to the reported circumstances and to determine how these corresponded to views in early adulthood about its timing.

Design: Cross sectional study within a birth cohort using a questionnaire presented by computer.

Setting: Dunedin, New Zealand in 1993-4.

Subjects: 477 men and 458 women enrolled in the Dunedin Multidisciplinary Health and Development Study, comprising $92 \%$ of survivors of the cohort. Results: The median age at first intercourse was 17 years for men and 16 years for women. Only one man $(0.2 \%)$ but $30(7 \%)$ women reported being forced to have intercourse on the first occasion. For women, there were increasing rates of coercion with younger age at first intercourse. More men than women reported that they and their partner were equally willing (77\% (316/413) v 53\% (222/419)). Mutual willingness of both partners was greater for those who reported that it was also the first time for their partner. Timing of first intercourse was considered about right by $49 \%(200 / 411)$ of men and $38 \%$ (148/388) of women. Many women (54\% (211/388) reported that they should have waited longer, and this rose to $70 \%(90 / 129)$ for women reporting intercourse before age 16 .

Conclusions: Most women regretted having sexual intercourse before age 16. First intercourse at younger
\end{abstract}

ages is associated with risks that are shared unequally between men and women. This information is important to young people themselves.

\section{Introduction}

In many developed countries, including New Zealand, there has been a substantial lowering of the age at first sexual intercourse over the past 30 years. ${ }^{1}$ Early intercourse carries increased risks of sexually transmitted diseases and unwanted pregnancies, which may result in long term health and social disadvantages. ${ }^{23}$

Individual (physical and social) and societal factors influence adolescent sexual behaviour. ${ }^{4}$ Children are exposed to sexual images through the media. Social and peer pressure may arise from the portrayal of sex as glamorous, pleasurable, and adult, while negative consequences and the responsibilities involved in sexual relationships are seldom portrayed. ${ }^{5}$ Although more liberal attitudes of society have influenced the behaviour of the current generation of young people, few studies have considered the views of young people themselves about early intercourse ${ }^{4-8}$ even though they have to bear the consequences.

The aim of our study was to investigate the circumstances of first sexual intercourse and to determine how these corresponded to views in early adulthood about its timing. Of interest was the extent of the differences in views between young men and women who reported similar sexual behaviour.
Department of Preventive and Social Medicine, University of Otago Medical School, PO Box 913, Dunedin, New Zealand Nigel Dickson senior research fellow Charlotte Paul associate professor of epidemiology Peter Herbison biostatistician

Dunedin Multidisciplinary Health and Development Unit, University of Otago Medical School Phil Silva director

Correspondence to: Dr Dickson (ndickson@gandalf. otago.ac.nz)

BMJ 1998;316:29-33 


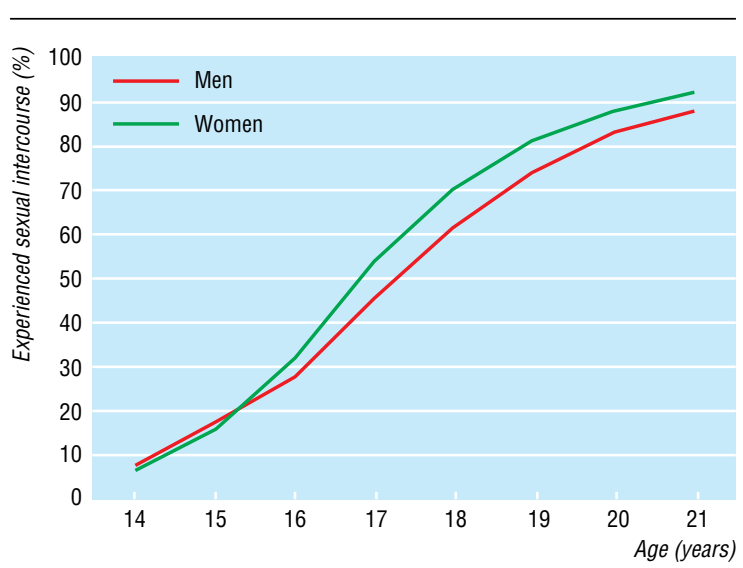

Cumulative rates of reported age of first heterosexual intercourse among 477 men and 458 women

\section{Methods}

Our subjects were enrolled in the Dunedin multidisciplinary health and development study, a longitudinal study of a cohort born in Dunedin in 1972-3, which has been described elsewhere. ${ }^{9}$ At age 18 years, subjects were asked about their sexual behaviour in the previous 12 months, and, at age 21, were questioned more extensively about their sexual behaviour and attitudes. The subjects generally returned to Dunedin for this assessment, even if they were living overseas.

Many of the questions were based on the 1990 British national survey of sexual attitudes and lifestyles. ${ }^{610}$ The subjects were presented with questions by computer and were informed that double

Table 1 Reported age at first sexual intercourse and willingness of respondent and first sexual partner (values are numbers (percentages))

\begin{tabular}{|c|c|c|c|c|c|}
\hline \multirow[b]{2}{*}{ Age (years) } & \multirow[b]{2}{*}{$\begin{array}{c}\text { Self more } \\
\text { willing }\end{array}$} & \multirow[b]{2}{*}{$\begin{array}{c}\text { Both equally } \\
\text { willing }\end{array}$} & \multicolumn{2}{|c|}{ Partner more willing } & \multirow[b]{2}{*}{$\begin{array}{l}\text { Cannot } \\
\text { remember or } \\
\text { not stated }\end{array}$} \\
\hline & & & $\begin{array}{c}\text { Self also } \\
\text { willing or } \\
\text { persuaded }\end{array}$ & Self forced & \\
\hline \multicolumn{6}{|l|}{ Men } \\
\hline$\leqslant 13(n=35)$ & $3(9)$ & $24(69)$ & $4(11)$ & 0 & $4(11)$ \\
\hline $14-15(n=94)$ & $9(10)$ & $70(75)$ & $6(6)$ & 0 & $9(10)$ \\
\hline 16-17 (n=159) & $11(7)$ & $119(75)$ & $23(15)$ & $1(1)$ & $5(3)$ \\
\hline $18-19(n=101)$ & $8(8)$ & $81(80)$ & $8(8)$ & 0 & $4(4)$ \\
\hline $20-21(n=24)$ & $1(4)$ & $22(92)$ & $1(4)$ & 0 & 0 \\
\hline Total $(n=413)$ & $32(8)$ & $316(77)$ & $42(10)$ & $1(<1)$ & $22(5)$ \\
\hline \multicolumn{6}{|l|}{ Women } \\
\hline$\leqslant 13(n=28)$ & 0 & $9(32)$ & $12(43)$ & $7(25)$ & 0 \\
\hline $14-15(n=117)$ & 0 & $59(50)$ & $42(36)$ & $9(8)$ & $7(6)$ \\
\hline $16-17(n=175)$ & $2(1)$ & $91(52)$ & $62(35)$ & $13(7)$ & $7(4)$ \\
\hline $18-19(n=80)$ & $3(4)$ & $50(63)$ & $25(31)$ & $1(1)$ & $1(1)$ \\
\hline $20-21(n=19)$ & 0 & $13(68)$ & $6(32)$ & 0 & 0 \\
\hline Total $(n=419)$ & $5(1)$ & $222(53)$ & $147(35)$ & $30(7)$ & $15(4)$ \\
\hline
\end{tabular}

Table 2 Reported willingness at first sexual intercourse of respondent and sexual partner, who was reported to be the same age (within 1 year), by age at first intercourse. (Values are numbers (percentages))

Age at first intercourse

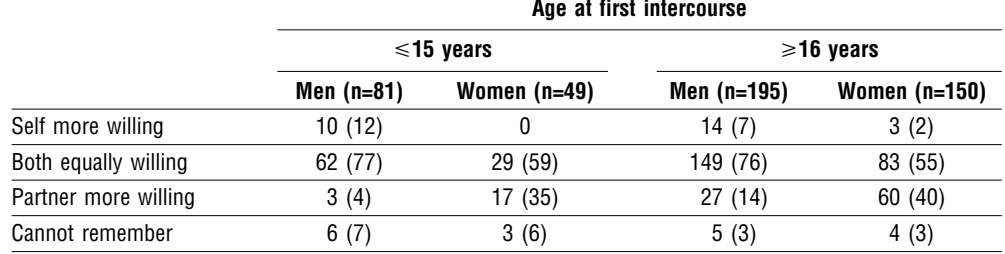

coding would make their responses anonymous. Those subjects who reported having had heterosexual intercourse were asked about their first experience. Subjects were also asked about occurrence of sexually transmitted diseases, as has been described elsewhere. ${ }^{11}$

To examine repeatability of reporting of age at first intercourse, we compared the responses made at the two assessments of the subjects who reported at the second assessment (at age 21) that they had had intercourse after the age at which they attended the first assessment (at age 18).

We compared answers with $\chi^{2}$ tests by means of the statistical package Epi-Info. ${ }^{12}$

\section{Results}

Of the 1037 members of the cohort formed at age 3 years, $935(92 \%)$ of the 1020 survivors completed the questions on sexual behaviour at age 21 . Of the 477 men, 419 (88\%) reported having had heterosexual intercourse (two did not answer this question). Of the 458 women, 421 (92\%) reported having had heterosexual intercourse. The median age of first intercourse was 17 years for men and 16 years for women. Of the men, 28\% (129/469) reported having had intercourse at age 15 or less, as did $32 \%(145 / 457)$ of the women (figure). Eight men and one woman did not give an age. Among the subjects for whom such a comparison was possible, $94 \%$ (112/119) of men and 98\% (183/187) of women were consistent in their reporting of age at first intercourse at the assessments for 18 year olds and 21 year olds.

Table 1 shows that, whereas $77 \%$ of men reported that they and their partners were "equally willing," only $53 \%$ of women reported this. Only one man $(0.2 \%)$ but $7 \%$ of women reported that their first episode of intercourse was "forced." For women, but not for men, there was a tendency for those having earlier intercourse to be more likely to report being forced. For both sexes, with increasing age at first intercourse, more subjects reported that they and their partner were equally willing.

To determine whether gender differences in reported willingness were due to different ages of partners, we did an analysis restricted to those who reported the age of their first partner to be within one year of their own (table 2). In this subgroup there were few differences from the main cohort (table 1), and the differences between men and women were similar among those with earlier and later first intercourse. Hence age differentials did not seem to be driving the gender differences in reported willingness.

In contrast, an analysis restricted to men and women who reported that it was also their partners' first intercourse found no gender differences in reports of both being equally willing (table 3 ). There were much smaller differences between the proportion of men reporting themselves as more willing and the proportion of women reporting their partners as more willing, and vice versa, and these differences were not significant.

When asked to reflect on their first intercourse (excluding those who reported being forced, who were not asked), $16 \%$ of men but $54 \%$ of women reported that they "should have waited longer before having sex with anyone," while $11 \%$ of men but only $1 \%$ of women 
reported that they "should not have waited so long" (table 4). There was also a marked gender difference in those who responded "don't know or no opinion." For women only, those who first had sex at younger ages were more likely to say that they should have waited longer. For both sexes, subjects who were older at first intercourse were more likely to report that it was about the right time. But the proportion of men who thought that they waited too long was not related to age.

Being "curious about what it would be like" was the commonest reason given by both sexes for first intercourse (table 5). Fewer men than women reported the main reason as being "carried away by [their] feelings" or being "in love," and more men than women reported that they "wanted to lose [their] virginity." Ten per cent of both sexes reported the main reason as being "a bit drunk at the time," and more reported alcohol as being one factor. Men who first had intercourse under the age of 16 were significantly more likely to report the main reason to be curiosity, and less likely to report being in love, than later initiators. Women who first had intercourse under age 16 were more likely to report the main reason to be that "most people of [their] age were doing it" and were also less likely to report being in love than later initiators.

More men had "just met [their partner] for the first time," and fewer were in a "steady relationship." Similarly, more men reported having had sex only once with their first partner, and for fewer men the relationship continued for more than one year. For half the men but $30 \%$ of women, first intercourse happened "on the spur of the moment." Men were more likely to be the same age or older than their first partner, and women more likely to be younger. First intercourse before age 16 for men was more commonly associated with a transient relationship than later intercourse, and less commonly associated with alcohol consumption. For women, these factors did not seem to be age related.

There were differences in the circumstances of first intercourse between those who reported that it was also their partner's first time and the remainder. The former group were more likely to be in a "steady relationship" (54\% v 24\% for men, 84\% v 41\% for women), more likely to have planned the event with their partner (21\% v 5\% for men, $28 \% v 10 \%$ for women), less likely to have been influenced by alcohol (17\% v 28\% for men, $9 \%$ v $23 \%$ for women), and less likely to have no subsequent relationship (23\% v 47\% for men, and $11 \%$ v $29 \%$ for women).

Sexually transmitted diseases were reported by $13 \%$ of men who first had intercourse under 16 years old and by $6 \%$ of later initiators. The corresponding proportions for women were $28 \%$ and $12 \%$.

Table 3 Reported willingness at first sexual intercourse of respondent and of sexual partner for whom it was also the first intercourse. (Values are numbers (percentages))

\begin{tabular}{lcc} 
& Men $(\mathbf{n}=\mathbf{1 2 3})$ & Women $(\mathbf{n}=\mathbf{8 6})$ \\
\hline Self more willing & $13(11)$ & $1(1)$ \\
\hline Both equally willing & $100(81)$ & $68(79)$ \\
\hline Partner more willing & $7(6)$ & $16(19)$ \\
\hline Cannot remember & $3(2)$ & $1(1)$ \\
\hline
\end{tabular}

Table 4 Men's and women's views, at age 21, of timing of their first sexual intercourse (excluding those who reported being "forced" in first intercourse). (Values are numbers (percentages))

\begin{tabular}{|c|c|c|c|c|}
\hline $\begin{array}{l}\text { Age at first } \\
\text { intercourse (years) }\end{array}$ & $\begin{array}{c}\text { Should have waited } \\
\text { longer }\end{array}$ & About right & $\begin{array}{l}\text { Should not have } \\
\text { waited so long }\end{array}$ & $\begin{array}{l}\text { Don't know or } \\
\text { no opinion }\end{array}$ \\
\hline \multicolumn{5}{|l|}{ Men } \\
\hline$\leqslant 13(n=35)$ & F8 (23) & $12(34)$ & $4(11)$ & $11(31)$ \\
\hline 14-15 (n=94) & $15(16)$ & $40(43)$ & $9(10)$ & $30(32)$ \\
\hline $16-17(n=157)$ & $21(13)$ & $79(50)$ & $18(12)$ & $39(25)$ \\
\hline $18-19(n=101)$ & $18(18)$ & $55(55)$ & $8(8)$ & $20(20)$ \\
\hline $20-21 \quad(n=24)$ & $2(8)$ & $14(58)$ & $4(17)$ & $4(17)$ \\
\hline Total $(n=411)$ & $64(16)$ & $200(49)$ & $43(11)$ & $104(25)$ \\
\hline \multicolumn{5}{|l|}{ Women } \\
\hline$\leqslant 13(n=22)$ & $16(73)$ & $2(9)$ & 0 & $4(18)$ \\
\hline $14-15(n=107)$ & $74(69)$ & $28(26)$ & 0 & $5(5)$ \\
\hline $16-17(n=162)$ & $91(56)$ & $61(38)$ & $1(1)$ & $9(6)$ \\
\hline $18-19(\mathrm{n}=78)$ & $23(30)$ & $47(60)$ & $2(3)$ & $6(8)$ \\
\hline $20-21(n=19)$ & F7 (37) & $10(53)$ & 0 & $2(11)$ \\
\hline Total $(n=388)$ & $211(54) \mathrm{F}$ & $148(38)$ & $3(1)$ & $26(7)$ \\
\hline
\end{tabular}

\section{Discussion}

In our study the median age at first intercourse was lower for women than for men; being "forced" at first intercourse was more common for women, especially girls who had intercourse before age 14; and reported mutual willingness at first intercourse and views on whether the timing was right differed substantially between men and women.

These findings are similar to what is known about recent sexual behaviour in Britain. Median age at first intercourse for the New Zealand women (16 years) was lower than for British women (17 years), while the age for men was the same (17 years). ${ }^{6}$ Convergence between men and women in age at first intercourse has been reported for younger cohorts in Britain. ${ }^{6}{ }^{7}$ In New Zealand we have observed a crossover in the past 20 years, with more women than men now having first intercourse before age 18. ${ }^{1}$ This has also been observed in Norway ${ }^{13}$ and Sweden $^{14}$ but not in the United States. ${ }^{15}$

Being forced at first intercourse was reported less commonly by women of all ages in the British national survey $(2 \%)^{67}$ compared with our study $(7 \%)$ or the American national survey (4\%). ${ }^{4}$ This may reflect cultural differences, but that fewer American women in younger cohorts wanted first intercourse to happen when it did suggests an increase in coercion in younger cohorts or at younger ages at first intercourse. Differences between men's and women's accounts of mutual willingness and timing were also more extreme in New Zealand than in Britain. ${ }^{6}$ Our results suggest that such differences may become greater in younger cohorts in Britain in the future.

\section{Reliability of study}

There are advantages in our sample and methods, including an unusually high response ${ }^{16}$; computer presentation, which seems to facilitate disclosure ${ }^{17}$; and the chance to check the repeatability of some responses at ages 18 and 21. Moreover, comparison of the responses at age 18 with national survey findings supports the likelihood of greater disclosure. ${ }^{18}$

Views of appropriateness of timing and willingness may be influenced by biased reporting. Respondents' conforming to social expectations should have been 
Table 5 Factors and circumstances reported to be associated with first sexual intercourse by to gender and age at first intercourse (excluding those who reported being "forced" in first intercourse). (Values are numbers (percentages) unless stated otherwise)

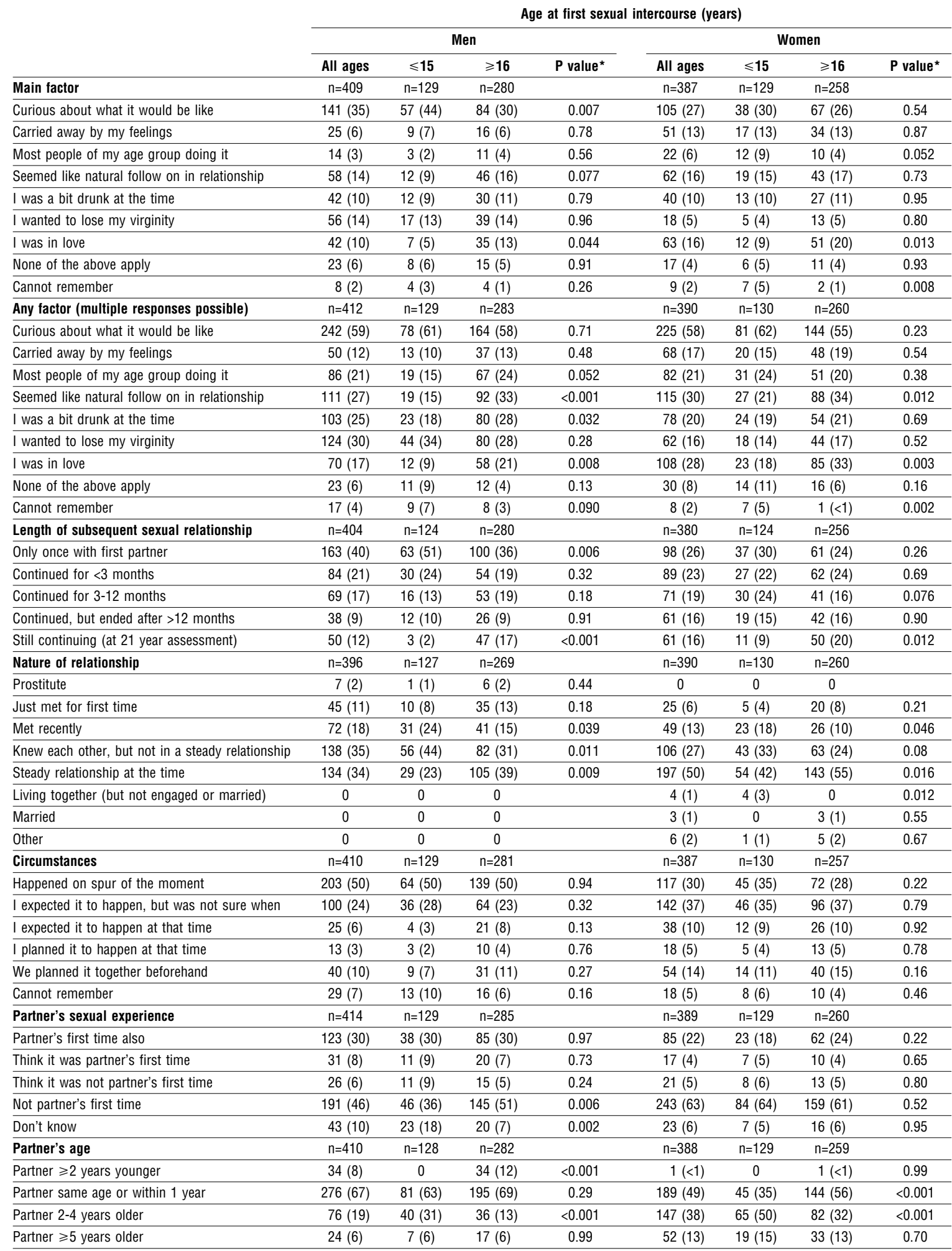

*Comparison between those who experienced first intercourse when aged $\leqslant 15$ years and those who experienced it when $\geqslant 16$ years.

minimised by the use of a computer presentation and anonymity. Gender based stereotyping in reported willingness is possible but is unlikely to be the main explanation because we found few gender differences in willingness for those who reported it was also the first time for their partner. Moreover, views constructed several years after first intercourse should not be construed simply as rationalisation of past events but, as Giddens suggests, as part of the narrative reconstruction of the past within which we make sense of our lives. ${ }^{19}$ What happens after first intercourse may be more important than what happens at the time in influencing subsequent regret. Considerably more young men than women were unable to give an opinion about past events, suggesting less reflection by young men, as others have found. ${ }^{20}$ 
Key messages

- We questioned a cohort of young New Zealand adults about the circumstances of their first sexual intercourse and their views about the timing of first intercourse

- Median age at first intercourse was 17 years for men and 16 years for women.

- Being forced at first intercourse was commonly reported by women, especially those who experienced intercourse before age 14, and most women who had intercourse before age 16 reported that they should have waited longer

- More men than women said that both they and their partner were equally willing at first intercourse, and reporting of equal willingness was greater among those who reported that it was also the first sexual intercourse for their partner

- As well as pronounced gender differences in mutual willingness and retrospective views of appropriate timing, more women reported occurrence of sexually transmitted disease, especially among those who had intercourse before age 16

\section{Gender differences}

Discrepancies between the interpretation of apparently similar events by young men and women were considerable. We found that $77 \%$ of men but only $53 \%$ of women claimed they were as equally willing as their partner at first intercourse, suggesting that, at younger ages, a gender difference in reported willingness remains despite convergence in behaviour. There are, however, difficulties in interpreting men's and women's reporting of their partner's willingness in a population sample. Only among those for whose partner it was also first intercourse could the accounts possibly match. In this subgroup the differences between men and women in reported willingness were much smaller. Though this is reassuring, the men and women who reported that their partner was also inexperienced were a special group who differed in other ways from the rest of the sample. It is not possible to sort these effects out, but is noteworthy that, for women, an inexperienced partner was associated with greater mutual willingness at any age at first intercourse up to 20 years.

Feelings about the timing of first intercourse also varied greatly by gender, especially for those reporting first intercourse before age 16 . This was not obviously related to the reasons given for first intercourse. The explanation for the apparent divergence of views of timing of first intercourse in this generation needs further examination. One factor may be that young women who reported having intercourse before age 16 were more likely to have an older partner. One implication of these findings is that earlier first intercourse is associated with risks that are shared unequally between young men and women. As well as pronounced gender differences in mutual willingness and retrospective views of appropriate timing, we found greater absolute differences in reported occurrence of sexually transmitted diseases in those reporting early intercourse.
The risks of early and unwanted pregnancies are also borne by women.

It is unclear whether young age at first intercourse was itself responsible for the lack of willingness and subsequent regret reported by many young women. Whatever the explanation, these results show that a substantial proportion of young women regret early intercourse. These findings need to be considered by young people themselves.

We thank Louise Garrett and Denise Powell for monitoring the interviews, and the other staff of the Dunedin multidisciplinary health and development study who were involved in the collection of the data and other aspects of the study. We appreciate the helpful comments of Tom Cunningham, Rob McGee, Libby Plumridge, David Skegg and Brigid Wilson. We particularly thank the sample members and their families for their long term involvement in the study.

Contributors: ND coordinated collection of data on sexual and reproductive health within the Dunedin multidisciplinary health and development study. He initiated and formulated the design of this analysis, wrote the first draft of the paper, and participated in the statistical analysis. CP was particularly involved in the development of core ideas, literature review, interpretation of data, and the writing of the paper. $\mathrm{PH}$ coordinated the computing aspects of the data collection and the statistical analysis. PS founded and directed the overall Dunedin multidisciplinary health and development study, including ethical aspects and study member relationships. He contributed to the editing of the paper. ND and CP are guarantors of the study.

Funding: This study was part of the Dunedin multidisciplinary health and development study and funded by the Health Research Council of New Zealand.

Conflict of interest: None.

1 Dickson NP, Paul C, Herbison P. Adolescents, sexual behaviour and implications for an epidemic of HIV/AIDS among the young. Genitourin Med 1993;69:133-40.

Stuart-Smith S. Teenage sex. BMJ 1996;312:390-1.

3 Hayes CD, ed. Risking the future. Washington DC: National Academy Press, 1987

Laumann EO, Gagnon JH, Michael RT, Michaels S. The social organisation of sexuality. Chicago: University of Chicago Press, 1994

5 Faculty of Public Health Medicine. Sex education for young people: a background review. London: Faculty of Public Health Medicine, 1995. (Guidelines for Health Promotion No 42.)

6 Johnson AM, Wadsworth J, Wellings K, Field J. Sexual attitudes and lifestyles. Oxford: Blackwell, 1994.

7 Wellings K, Field J, Johnson AM, Wadsworth J. Sexual behaviour in Britain. London: Penguin, 1994

8 Curtis A, Lawrence CJ, Tripp JH. Teenage sexual intercourse and pregnancy. Arch Dis Child 1988;63:373-9.

9 Silva PA, Stanton WR, eds. From child to adult:the Dunedin multidisciplinary health and development study. Auckland: Oxford University Press, 1996.

10 Johnson AM, Wadsworth J, Elliott P, Prior L, Wallace P, Blower S, et al. A pilot study of sexual lifestyle in a random sample of the population of Great Britain. AIDS 1989;3:135-41.

11 Dickson NP, Paul C, Herbison P, McNoe B, Silva P. The lifetime occurrence of sexually transmitted diseases among a cohort aged $21 . \mathrm{NZ}$ MedJ 1996;109:308-12.

12 Dean AG, Dean JA, Couloombier D, Brendel KA, Smith DC, Burton AH, et al. Epi Info, Version 6: a word processing, database, and statistics program for epidemiology on microcomputers. Atlanta, Georgia: Centers for Disease Control and Prevention, 1994.

13 Kraft P. Age of first intercourse among Norwegian adolescents: a lifetime perspective. Soc Sci Med 1991;2:207-13.

14 Lewin B. The adolescent boy and girl: first and other early experiences with intercourse from a representative sample of Swedish school adolescents. Arch Sex Behav 1982;11:417-29.

15 Centres for Disease Control. Sexual behaviour among high school students. MMWR CDC Surveill Summ 1992;40:885-8.

16 Wadsworth J, Johnson AM. Measuring sexual behaviour. J R Stat Soc 1991;154:367-70.

17 Millstein GM, Irwin CE. Acceptability of computer-acquired sexual histories in adolescent girls. J Pediatr 1983;103:815-9.

18 Paul C, Dickson NP, Davis PB, Yee RL, Chetwynd J, McMillan N. Heterosexual behaviour and HIV risk in New Zealand. Aust J Public Health 1995;19:13-8.

19 Giddens A. The transformation of intimacy. Cambridge: Polity Press, 1992.

20 Thompson S. Search for tomorrow: or feminism and the reconstruction of teen romance. In: Vance CS, ed. Pleasure and danger: exploring female sexuality. London: Pandora, 1989:350-84

(Accepted 3 September 1997) 